\title{
PERSEPSI PETANI MENABUNG DI BANK RAKYAT INDONESIA UNIT SONDER
}

\author{
Mario Arron Sumolang \\ Grace Adonia Josefina Rumagit \\ Lyndon Reinhard Jacob Pangemanan
}

\begin{tabular}{ll}
\hline Naskah diterima melalui Website Jurnal Ilmiah agrisosioekonomi @ unsrat.ac.id & : Sabtu, 13 Juli 2019 \\
Disetujui diterbitkan & : Kamis, 25 Juli 2019 \\
\hline
\end{tabular}

\begin{abstract}
The purpose of this study was to determine the perceptions of farmers saving at Bank Rakyat Indonesia Sonder Unit. This research has been carried out for three months, namely from April 2019 to June of 2019 starting from preparation to preparation of research reports. The sampling method in this study was intentional (purposive sampling) The data used in this study were primary and secondary data. Primary data is data obtained directly from 79 farmers who save at Bank Rakyat Indonesia Unit Sonder using a questionnaire. Secondary data is data obtained from PT. Bank Rakyat Indonesia Unit Sonder, such as data on consumer saving farmers. The analytical method used in this study is descriptive analysis method and uses Likert scale analysis. The results of this study indicate that the perception of farmers saving at Bank Rakyat Indonesia Unit Sonder belongs to the Satisfied category. ${ }^{*}$ prm ${ }^{*}$
\end{abstract}

Keyword: perception, farmers, saving, Sonder District

\section{ABSTRAK}

Tujuan penelitian ini adalah untuk mengetahui persepsi petani menabung di Bank Rakyat Indonesia Unit Sonder. Penelitian ini telah dilaksanakan selama tiga bulan yaitu dari bulan April 2019 sampai dengan bulan Juni Tahun 2019 dimulai dari persiapan sampai penyusunan laporan penelitian. Metode pengambilan sampel dalam penelitian ini secara sengaja (purposive sampling) Data yang digunakan dalam penelitian ini adalah data primer dan sekunder. Data Primer adalah data yang diperoleh secara langsung dari 79 konsumen petani yang menabung di Bank Rakyat Indonesia Unit Sonder dengan menggunakan daftar pertanyaan. Data Sekunder adalah data yang diperoleh dari PT. Bank Rakyat Indonesia Unit Sonder, seperti data konsumen petani penabung. Metode analisis yang digunakan dalam penelitian ini adalah metode analisis deskriptif dan menggunakan analisis skala likert. Hasil penelitian ini menunjukkan bahwa persepsi petani menabung di Bank Rakyat Indonesia Unit Sonder tergolong pada kategori Puas. *eprm*

Kata kunci: persepsi, petani, menabung, Kecamatan Sonder

\section{PENDAHULUAN}

\section{Latar Belakang}

Indonesia merupakan negara agraris dengan luas lahan yang sebagian besar dikelola untuk pertanian dan keaneka ragaman hayati yang sangat beragam.Di negara agraris seperti Indonesia sektor pertanian mempunyai kontribusi penting baik terhadap perekonomian maupun terhadap pemenuhan kebutuhan pokok masyarakat karena sebagian besar penduduknya hidup dari hasil bercocok tanam atau bertani. Sektor pertanian terdiri dari sub sektor tanaman pangan, hortikultura, perkebunan, dan peternakan. Dari keempat sub sektor tersebut, hortikultura merupakan salah satu sub sektor yang terus berkembang dan mempunyai peranan penting dalam peningkatan pendapatan masyarakat.

Bank merupakan salah satu lembaga keuangan yang kegiatan utamanya adalah meminjamkan uang yang disimpan kepadanya. Lembaga keuangan ini akan mendorong masyarakat untuk menyimpan uangnya, dengan diberi balas jasa sebagai pendapatannya berupa bunga atas 
simpanannya. Simpanan yang terkumpul oleh bank akan dipinjamkan kembali kepada perorangan atau perusahaan yang membutuhkannya. Dalam bisnis dunia perbankan, pelayanan berkualitas menyangkut bagaimana cara pegawai bank memperlakukan nasabah sedemikian rupa sehingga dia memperoleh persepsi positif dari nasabah. Kepercayaan masyarakat amat penting artinya bagi seluruh bank karena akan dapat meningkatkan jumlah nasabah dan menghimpun dana untuk keperluan operasionalnya.,Rifai(2015).

Salah satu produk perbankan adalah tabungan. Untuk dapat menarik minat masyarakat agar menabung uangnya di bank tersebut, maka pihak perbankan selalu melakukan inovasi terhadap produk tabungannya dengan berbagai macam fitur/fasilitas. Hal tersebut dilakukan dengan tujuan untuk dapat mengakomodasi seluruh kebutuhan nasabah dan memberikan kemudahan-kemudahan kepada nasabah untuk melakukan seluruh keperluan aktivitas keuangannya.

Perkembangan positif dunia saat ini telah membawa para pelaku perbankan ke persaingan yang sangat ketat untuk memperebutkan nasabah. Berbagai pendekatan untuk berebut dana dari masyarakat baik melalui peningkatan sarana dan prasarana berfasilitas teknologi tinggi maupun dengan pengembangan sumber daya manusia agar mampu memberikan pelayanan terbaik kepada nasabah telah dilakukan.

PT. Bank Rakyat Indonesia adalah salah satu bank yang melakukan kegiatan perbankan di Indonesia dan memiliki beberapa cabang diseluruh Indonsia, PT..Bank Rakyat Indonesia Tbk, Unit Sonder merupakan salah satu bank yang melakukan kegiatan operasionalnya di wilayah Minahasa Kecamatan Sonder, yang saat ini terus berupaya memberikan pelayanan yang terbaik kepada nasabahnya. Keberadaan Bank Rakyat Indonesia Tbk, Unit Sonder dapat menghimpun dana dari masyarakat Kecamatan Sonder dengan membuka rekening tabungan. Masyarakat yang menjadi Nasabah di Bank Rakyat Indonesia Tbk, terdiri dari berbagai jenis pekerjaan, yaitu petani, pedagang, pegawai, buruh dan pelajar. Di dalam sektor pertanian menabung juga penting bagi para petani karena dapat menyimpan hasil pertaniannya. Salah satu faktor penting bagi petani untuk menabung karena hasil dari pertanian tidak selalu ada di tiap bulan karena ada jarak antara musim tanam dan panen bagi para petani.

Bank Rakyat Indonesia unit Sonder dapat melakukan berbagai cara untuk menarik perhatian petani dalam meningkatkan jumlah penabungnya, seperti dengan memberikan tingkat pelayanan yang baik, dan jaminan keamanan dari pemerintah terhadap dana yang disimpan. Proses tersebut secara otomatis akan mempromosikan Bank Rakyat Indonesia Unit Sonder menjadi lebih baik dibandingkan bank lainnya. Menurut data dari Bank BRI Cabang Sonder ( 2018) petani penabung di bank BRI unit sonder cenderung meningkat dari tahun ke tahun pada tahun 2016 jumlah petani penabung 328 nasabah kemudian menjadi peningkatan pada tahun 2017 berjumlah 390 dan pada tahun 2018 berjumlah 392 peningkatan terjadi karena adanya pelayanan yang baik bagi nasabah untuk itu perluh diteliti persepsi petani menabung terhadap bank BRI.

\section{Rumusan Masalah}

Berdasarkan uraian diatas, maka yang menjadi permasalah dalam penelitian ini adalah bagaimana persepsi petani dalam menabung di Bank Rakyat Indonesia?

\section{Tujuan Penelitian}

Tujuan penelitian adalah untuk mengetahui persepsi petani dalam menabung di Bank Rakyat Indonesia unit Sonder.

\section{Manfaat Penelitian}

Penelitian ini harapkan dapat memberikan informasi bagi petani di Kecamatan Sonder yang ingin menabung di Bank Rakyat Indonesia dapat mengetahui bagaimana cara menabung dan keuntungan dalam menabung di bank Bank Rakyat Indonesia Unit Sonder.

\section{METODE PENELITIAN}

\section{Waktu Dan Tempat Penelitian}

Penelitian ini telah dilaksanakan selama tiga bulan yaitu dari bulan April 2019 sampai dengan bulan Juni tahun 2019 dimulai dari persiapan sampai penyusunan laporan penelitian. Tempat penelitian di PT. Bank Rakyat Indonsia Unit Sonder Kecamatan Sonder Kabupaten Minahasa.

\section{Jenis-jenis Data}

Data yang digunakan dalam penelitian ini adalah data primer dan sekunder

1) Data Primer adalah data yang diperoleh secara langsung dari konsumen petani yang menabung di bank dengan menggunakan daftar pertanyaan.

2) Data Sekunder adalah data yang diperoleh dari PT. Bank Rakyat Indonesia Tbk.Unit Sonder, seperti data konsumen petani penabung. 


\section{Metode Pengambilan Sampel}

Sampel adalah sebagian dari populasi yang karakteristiknya hendak diselidiki dan dianggap bisa mewakili keseluruhan populasi (jumlahnya lebih sedikit daripada populasinya).

1) Populasi

Populasi dari penelitian ini adalah seluruh petani penabung Bank BRI unit Sonder sebanyak 392 nasabah petani penabung Tahun 2018 yang aktif sampai sekarang.

2) Sampel

Metode pengambilan sampel dalam penelitian ini adalah purposive sampling, teknik ini tidak berdasarkan random, daerah, atau strata. Melaikan berdasarkan atas adanya pertimbangan yang berfokus pada tujuan tertentu, teknik purposive sampling juga merupakan teknik pengambilan sampel yang dilakukan secara sengaja dan telah sesuai dengan semua persyaratan meliputi; sifat-sifat,karakteristik,ciri, dan kriteria sampel tertentu. Pengambilan sampel juga harus mencerminkan populasi dari sampel itu sendiri. Untuk menghitung besarnya sampel digunakan rumus slofin sebagai berikut: (Marzuki dalam Sunyoto 2014)

Keterangan :

$$
n=\frac{N}{N\left(d^{2}\right)+1}
$$

$\mathrm{N}=$ Jumlah populasi (semua nasabah petani

$\mathrm{n}=$ Jumlah sampel yang digunakan

$\mathrm{d}=(1-$ tk. Ketepatan $)$

Tingkat ketepatan yang digunakan dalam penelitian ini adalah sebesar 0.90 .

$$
\begin{aligned}
& n=\frac{3952}{392\left(0.1^{2}\right)} n=\frac{392}{3.92+1} \quad n=\frac{392}{4.92}=79.6747967 \\
& \mathrm{~N}=39 \mathrm{n}=79 \quad \mathrm{~d}=0,1
\end{aligned}
$$

Berdasarkan perhitungan diatas, maka jumlah responden yang digunakan dalam penelitian ini adalah sebanyak 79 responden, yaitu nasabah yang menabung di bank BRI unit Sonder.

\section{Konsep Pengukuran Variabel}

Variabel yang diteliti terhadap konsumen petani yang menabung di bank BRI adalah sebagai berikut:

1. Karakteristik Responden,meliputi:

a. Jenis Kelamin (laki-laki/perempuan)

b. Umur (Tahun)

c. Tingkat Pendidikan (Pendidikan Terakhir Konsumen)
Variabel persepsi petani menabung PT. Bank Rakyat Indonesia unit Sonder yang di ukur sebagai berikut;

A. Jaminan (Assurance)

Jaminan adalah asset pihak peminjam jika peminjam tidak dapat mengembalikan pinjaman tersebut, jika peminjam gagal bayar, pihak pemberi pinjaman dpat memiliki agunan tersebut. Jaminan yaitu pengetahuan, kesopansantunan, dan kemampuan pegawai perusahaan untuk membutukan rasa percaya pelanggan kepada perusahaan, indicatorindikatornya:

1) Karyawan bersikap sopan dalam menangani konsumen

2) Ketelitian karyawan dalam melayani konsumen

3) Keamanan dalam melakukan transaksi

4) Kejelasan informasi

B. Suku bunga

Bunga adalah harga yang harus di bayar oleh bank atau nasabah sebagai balas jasa atas transaksi antara pihak bank dan nasabah,

1). Suku Bunga Penabung

C. Hadiah adalah pemberian berupa uang, barang, atau jasa yang dilakukan pihak tertentu kepada konsumen atau orang

1). Hadiah

D. Promosi

Promosi adalah sejenis komunikasi yang memberi penjelasan yang meyakinkan calon konsumen tentang barang dan jasa.

1). Tingkat promosi

2). Macam promosi

E. Lokasi

Lokasi dalam penentuan lokasi berhubungan dengan keputusan yang dibuat oleh perusahaan mengenai dimana operasi dan stafnya akan ditempatkan.

1). Lokasi

\section{Metode Analisis Data}

Analisis data yang digunakan untuk mengetahui persepsi petani menabung pada bank BRI, menggunakan kriteria tingkat kepuasan konsumen berdasarkan alat ukur skala likert. Menurut Soegiyono dalam Sunyoto (2014) skala likert adalah skala yang digunakan untuk mengukur sikap, pendapat, dan persepsi seseorang atau kelompok orang tentang fenomena seseorang. 


\section{HASIL DAN PEMBAHASAN}

\section{Deskripsi Umum Tempat Penelitian}

Bank Rakyat Indonesia adalah salah satu bank milik pemerintah terbesar di Indonesia. Pada awalnya Bank Rakyat Indonesia (BRI) didirikan di Purwekerto Jawa Tengah oleh Raden Bei Aria Wiraadmadja. Lembaga tersebut didirikan tanggal 16 Desember1895, yang kemudian dijadikan sebagai hari kelahiran BRI. Sejak 1 Agustus 1992 berdasarkan Undang-Undang Perbankan Nomor 7 tahun 1992 dan peraturan pemerintah RI Nomor 21 tahun 1992 status BRI beruba menjadi perseroan terbatas. Kepemilakan BRI saat itu masih 100 persen milik pemerintah RI. Paada tahun 2003, Pemerintah Indonesia memutuskan menjual 30 persen saham bank ini, sehingga menjadi perusahaan publik dengan nama resmi PT. Bank Rakyat Indonesia (persero) Tbk yang masih digunakan sampai dengan saat ini. Lokasi penelitian ini bertempat pada kantor BRI Unit Sonder, yang beralamatkan Desa Tounelet Kecamatan Sonder bank ini memiliki tempat yang bagus yang berada di pusat kecamatan sonder yang aksesnya mudah dijangkau karena ada dipinggiran jalan besar dan dekat dengan kantor pos, kantor kecamatan dan juga dekat pasar.

\section{Karakteristik Responden}

Jumlah responden pada penelitian ini berjumlah 79 orang petani yang menabung pada Bank Rakyat Indonesia Unit Sonder. Gambaran umum mengenai responden disajikan menurut jenis kelamin, umur, dan tingkat pendidikan.

\section{Umur Responder}

Setiap responder bank BRI sudah pasti tidak sama, demikian juga dengan umur masing-masing konsumen, Tabel 1 menunjukkan jumlah responder terbanyak pada umur $\geq 51$ tahun ke atas dengan jumlah 38 konsumen dengan presentasi sebesar $48.1 \%$ sedangkan jumlah sampel dengan tingkat umur terendah pada interval $21-30$ tahun dengan jumlah konsumen 6 dengan presentasi $7.5 \%$.
Tabel 1. Jumlah Responden Menurut Umur

\begin{tabular}{llll}
\hline No & Umur (tahun) & Jumlah Responden & Persentase $(\%)$ \\
\hline 1 & $21-30$ & 6 & 7.6 \\
2 & $31-40$ & 7 & 8.9 \\
3 & $41-50$ & 28 & 35.4 \\
4 & $\geq 51$ & 38 & 48.1 \\
\hline & Jumlah & 79 & 100 \\
\hline
\end{tabular}

Sumber : Diolah dari data primer,2018

\section{Tingkat Pendidikan}

Tingkat pendidikan dari masing-masing orang berbeda, begitu juga dengan tingkat pendidikan dari masing-masing konsumen yang menabung di bank BRI unit Sonder.

Tabel 2 dibawah menunjukkan bahwa tingkat pendidikan responder yang terbanyak yaitu pada tingkat pendidikan SMA dengan jumlah 46 orang dengan presentasi $58.2 \%$. sedangkan tingkat pendidikan responden paling sedikit dengan tingkat pendidikan $\mathrm{S} 1$ dengan jumlah 2 orang dengan presentasi $2.5 \%$.

Table 2. Jumlah Responden Menurut Tingkat Pendidikan

\begin{tabular}{llll}
\hline No & Tingkat Pendidikan & Jumlah Responden & Persentase $(\%)$ \\
\hline 1 & SD & 22 & 27.9 \\
2 & SMP & 9 & 11.3 \\
3 & SMA & 46 & 58.2 \\
4 & S1 & 2 & 2.6 \\
\hline & Jumlah & 79 & 100
\end{tabular}

Sumber : Diolah dari data primer,2018

\section{Jenis Kelamin}

Tabel 3 dibawah ini menunjukkan jenis kelamin dari konsumen petani menabung di bank BRI unit Sonder. Sebagian besar responden adalah laki-laki dengan jumlah 49 dengan presentasi $62.1 \%$ Sedangkan perempuan dengan jumlah 30 dengan presentasi $37.9 \%$.

Tabel 3. Jumlah Responden Menurut Jenis Kelamin

\begin{tabular}{llcr}
\hline No & Jenis kelamin & Jumlah Responden & Persentase (\%) \\
\hline 1 & Laki-laki & 49 & 62.1 \\
2 & Perempuan & 30 & 37.9 \\
\hline \multicolumn{4}{l}{ Jumlah } \\
\hline \multicolumn{2}{l}{ Sumber : Diolah dari data primer,2018 }
\end{tabular}

\section{Persepsi Petani Terhadap Jaminan}

Jaminan yaitu pengetahuan, kesopansantunan, dan kemampuan pegawai perusahaan untuk membutuhkan rasa percaya pelanggan kepada perusahaan.

Tabel 4 menunjukkan bahwa terdapat 4 indikator terhadap jaminan, indicator dengan jumlah indeks kepuasan konsumen paling tinggi adalah indicator 4 yaitu $86.3 \%$, selanjutnya pernyataan 2 yaitu $79.7 \%$, selanjutnya penyataan 3 yaitu $79.4 \%$ dan selanjutnya pernyataan 1 yaitu $78.4 \%$. 
Tabel 4 . Rekapitulasi Petani Menabung Terhadap Jaminan

\begin{tabular}{llccc}
\hline No & Pernyataan & Total Skor & $\begin{array}{c}\text { Indeks } \\
\text { Kepuasan }(\%)\end{array}$ & Interpretasi \\
\hline 1 & $\begin{array}{l}\text { Karyawan } \\
\text { bersikap sopan } \\
\text { dalam menangani } \\
\text { konsumen }\end{array}$ & 310 & 78.4 & Puas \\
2 & $\begin{array}{l}\text { Ketelitian } \\
\text { karyawan dalam } \\
\text { melayani }\end{array}$ & 315 & 79.7 & Puas \\
konsumen & $\begin{array}{l}\text { Keamanan dalam } \\
\text { melakukan } \\
\text { transaksi }\end{array}$ & 314 & 79.4 & Puas \\
\hline & $\begin{array}{l}\text { Kejelasan } \\
\text { informasi }\end{array}$ & 341 & 86.3 & Sangat Puas \\
\hline Sumber : Diolah dari data primer, 2018 & &
\end{tabular}

Berkaitan dengan karyawan bersikap sopan dalam melayani konsumen, total skor yang di capai 310, sehngga angka indeks kepuasan adalah sebesar $78.4 \%$, ini menunjukkan nilai tergolong puas. Karena konsumen merasa puas dengan kesopanan karyawan dalam melayani konsumen, sikap karyawanpun sopan terhadap pelayanan konsumen.

Dalam hal ketelitian karyawan dalam melayani konsumen, total skor yang konsumen di capai 315, sehingga angka indeks persepsi adalah $79.7 \%$, ini menunjukkan nilai tergolong puas. Karena konsumen merasa puas dengan ketelitian karyawan dalam melayani konsumen.

Mengenai keamanan dalam melakukan transaksi, total skor yang di capai 314, sehingga angka indeks persepsi adalah sebesar 79.4\% ini menunjukkan bahwa interpretasi nilainya tergolong puas. Konsumen merasa sangat puas dengan keamanan bank BRI dalam melakukan transaksi karena pihak bank BRI menyediakan security untuk keamanan dalam bank BRI.

Sehubungan dengan kejelasan informasi yang di berikan karywana terhadap konsumen total skor yang di peroleh 341, sehingga angka indeks kejelasan informasi adalah $86.3 \%$. ini menunjukkan bahwa nilai tergolong sangat puas, karena kaywan mamou meberikan kejelasan informasi terhadap konsumen dengan baik dan benar sehingga konsumen merasa sangat puas dengan pelayanan karyawan.

\section{Persepsi petani terhadap suku bunga}

Bunga adalah harga yang harus di bayar oleh bank atau nasabah sebagai balas jasa atas transaksi antara pihak bank dan nasabah.

Berkaitan dengan suku bunga konsumen dicapai sebesar 335, sehingga indeks kepuasan konsumen adalah sebesar 84.8\%, sehingga menunjukkan interpretasi sangat puas. Karena konsumen merasa bahwa suku bunga bank masih bisa diatasai oleh konsumen atau konsumen masih merasa sangat puas dengan suku bunga tersebut.

\section{Persepsi petani terhadap hadiah}

Hadiah adalah pemberian dari seseorang atau kelompok berupa uang, barang, atau jasa yang dilakukan pihak tertentu kepada pihak lain atau orang. Berkaitan dengan skor variabel hadiah yang dicapai adalah sebesar 331, sehingga indeks kepuasan konsumen sebesar 83.7\%, sehingga menunjukkan iterpretasi sangat puas. Karena hadiah yang diberikan oleh pihak bank terhadap para konsumen membuat konsumen merasa sangat puas terhadap apresiasi dari pihak bank.

\section{Persepsi petani terhadap promosi}

Promosi adalah sejenis komunikasi yang memberi penjelasan yang meyakinkan calon konsumen tentang barang dan jasa. Tabel dibawah 5 menunjukkan bahwa terdapat 2 indikator terhadap indicator promosi dengan jumlah indeks kepuasan paling tinggi adalah indikator 2 dengan indeks kepuasan $66.3 \%$, selanjutnya indikator 1 dengan indeks kepuasan $55.9 \%$.

Tabel 5. Rekapitulasi petani menabung terhadap promosi

\begin{tabular}{llccc}
\hline No & Pernyataan & $\begin{array}{c}\text { Total } \\
\text { skor }\end{array}$ & $\begin{array}{c}\text { Indeks } \\
\text { kepuasan }(\%)\end{array}$ & Interpretasi \\
\hline 1 & $\begin{array}{l}\text { Tingkat } \\
\text { promosi }\end{array}$ & 221 & 55.9 & Cukup Puas \\
2 & $\begin{array}{l}\text { Macam } \\
\text { promosi }\end{array}$ & 262 & 66.3 & Puas \\
\hline \multicolumn{5}{l}{ Sumber : Diolah dari data primer,2018 }
\end{tabular}

Berkaitan dengan tingkat promosi karywan sebesar 221, sehingga indeks kepuasan 55.9\% sehingga menunjukkan interpretasi nilainya tergolong cukup puas, ini menunjukkan bahwa tingkat promosi yang di lakukan pihak bank harus lebih di tingkatkan lagi sehingga mampu membuat konsumen merasa puas.

Mengenai macam promosi total skor yang di peroleh adalah sebesar 262, sehingga angka indeks kepuasan mengenai macam promosi pada pada bank sebesar 66.3\%, sehingga interpretasi nilainya tergolong puas, konsumen merasa puas karena macam promosi yang diberikan pihak bank kepada konsumen sudah mampu membuat konsumen tertariik untuk menggunakan jasa bank BRI unit sonder untuk menabung.

\section{Persepsi petani terhadap lokasi}

Lokasi dalam penentuan lokasi berhubungan dengan keputusan yang dibuat oleh perusahaan mengenai dimana operasi dan stafnya akan ditempatkan atau suatu usaha atau aktivitas usaha yang dilakukan yang terpenting dalam pengembangan suaty usaha adalah letak lokasi terhadap daerah perkotaan, cara pencapaian dan waktu tempuh lokasi ketujuan. 
Mengenai persepsi petani menabung untuk lokasi bank memiliki total skor yang di peroleh sebesar 377, sehingga menunjukkan indeks kepuasan konsumen sebesar 95.4\%, sehingga menunjukkan interpretasi nilai tergolong sangat puas. Konsumen merasa sangat puas dengan lokasi bank karena sangat dekat dengan lokasi konsumen sehingga para konsumen tidak perluh lagi keluar kota untuk menggunakan jasa bank BRI unit Sonder.

Tabel 9. Rekapitulasi Persepsi Petani Terhadap Kelima Variabel.

\begin{tabular}{llccl}
\hline No & Variabel & Tota lskor & Indeks kepuasan & Interpretasi \\
\hline 1 & Jaminan & 1280 & 82.6 & Sangat Puas \\
2 & Suku Bunga & 335 & 84.8 & Sangat Puas \\
3 & Hadiah & 331 & 83.7 & Sangat Puas \\
4 & Promosi & 483 & 61.1 & Puas \\
5 & Lokasi & 377 & 95.4 & Sangat Puas \\
\hline \multicolumn{5}{l}{ sumber : Diolah dari data primer,2018 }
\end{tabular}

Tabel 9 menunjukkan bahwa variabel promosi yang terendah dari keempat variabel lainnya, hal ini disebabkan karena ada satu indikator dari promosi hanya mendapat angka indeks kepuasan sebesar $55.9 \%$ yang tergolong cukup puas yaitu indikator tingkat promosi. Hal ini dikarenakan nasabah melihat bahwa kurangnya promosi langsung dari karyawan kepada nasabah petani penabung, Ini menunjukkan bahwa pihak bank BRI harus memperhatikan strategi promosi yang merupakan komunikasi yang memberi penjelasan yang meyakinkan calon konsumen tentang barang dan jasa. Agar supaya bank BRI unit Sonder dapat menghadapi saingan pasar yang semakin kompetitif.

Sehubungan dengan variabel lokasi yang mendapatkan hasil tertinggi dari keempat variabel lainnya. Hal ini disebabkan karena lokasi bank BRI unit Sonder mudah di akses karena berdekatan dengan pemukiman warga setempat.

Untuk mengetahui letak persepsi petani dalam menabung di bank BRI unit Sonder, maka perluh di hitung jumlah keseluruhan skor pada setiap kriterium. Jumlah skor hasil penelitian ini 2.806. pada penelitian ini jumlah skor ideal (skor tertinggi), yaitu 3.555 (tingg) dan jumlah skor terendah 711 (rendah). Berdasarkan data yang di ambil dari 9 pernyataan yang di ajukan pada 79 responden, maka letak indeks motivasi petani menabung di bank BRI unit Sonder terletak pada :

Tingkat persepsi petani $=\frac{\text { Jumlah } s k o r \text { hasil pengumpulan data }}{\text { Jumlah skor ideal (Tertinggi) }}$ X $100 \%$

$$
\text { Tingkat persepsi petani }=\frac{2.806}{3.555} \times 100 \%=78,9 \%
$$

Dengan interpretasi nilai :

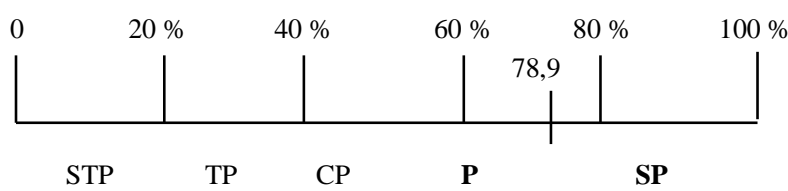

Keterangan kriteria interprestasi skor motivasi petani

Angka 0\%-20\%= Sangat Tidak Puas

Angka 20\%-40\%= Tidak Puas

Angka 40\%-60\% = Cukup Puas

Angka $60 \%-80 \%=$ Puas

Angka $80 \%-100 \%=$ Sangat Puas

Hasil perhitungan di atas menunjukkan angka indeks persepsi petani menabung di bank BRI unit Sonder sebesar $78.9 \%$, artinya secara umum nasabah penabung tergolong puas.

\section{KESIMPULAN DAN SARAN}

\section{Kesimpulan}

Hasil penelitian menunjukkan bahwa persepsi petani menabung di Bank Rakyat Indonesia (BRI) Unit Sonder tergolong kategori puas berkaitan dengan kelima variabel yang di teliti yaitu tentang jaminan, suku bunga, hadiah, promosi, dan lokasi.

\section{Saran}

Untuk meningkatkan lagi persepsi petani dalam menabung melalui kelima variabel yaitu jaminan, suku bunga, hadiah, promosi,dan lokasi, maka pihak Bank BRI Unit Sonder harus meningkat daya tarik dari pihak Bank untuk para petani penabung dengan memperhatikan promosi karena tergolong kategori puas, sedangkan variabel yang lain tergolong kategori sangat puas. Hal ini harus lebih diperhatikan lagi oleh pihak bank BRI unit Sonder agar bisa mendapatkan nasabah lebih banyak lagi.

\section{DAFTAR PUSTAKA}

Bank Rakyat Indonesia (BRI) unit Sonder Kecamatan Sonder, Nasabah menabung 2016, 2017, DAN 2018

Rifai, 2015, Analisis prilaku Petani dalam menabung di PT Bank Danamon Indonesia TBK, unit Danamon simpan Pinjam bagan batu. Skripsi Fakultas Pertanian universitas Riau.

Suyotno,M.M. 1999, Djuhaepah T. marala,MBH., Azhar Abdullah SH., Johan Thomas A[onno, Dra. C. Tinon Yuniati Ananda, Drs. H.A. Chalik 1999. KELEMBAGAAN PERBANKAN, Edisi Ketiga, PT Gramedia Pustaka Utama. 